\title{
AIRFARE DISCOUNTS TO 91ST ANNUAL MEETING
}

The American Political Science Association, in cooperation with United Airlines and World Travel Partners, has arranged for special airfare discounts to attendees of the 91st Annual Meeting, to be held August 31 - September 3, 1995 in Chicago.

United Airlines, the official carrier for the APSA Annual Meeting, is offering $5 \%$ off all discounted published fares or $10 \%$ off unrestricted coach fares on travel to Chicago.

To reserve your flight, call either United Airlines directly, or APSA's official travel coordinator, World Travel Partners, at the numbers and times listed below.

\section{World Travel Partners \\ (800) 336-0227 or (703) 205-0445 \\ Monday - Friday, 9:00 a.m. - 5:30 p.m. (EST)}

In addition to low, economical airfares, by booking your flight with World Travel Partners you automatically receive:

* $\$ 200,000$ flight insurance

* Seat assignments

* Credit for Frequent Flyer mileage

* Lowest fares available on all airlines

\section{United Airlines Meeting Desk}

(800) 521-4041

Monday - Friday, 7:00 a.m. - 12:00 midnight (EST)

Meeting ID\# 552FT

To take advantage of the best possible fares, please make your reservations early! Tickets must be booked at least seven days in advance to be eligible for the United Airlines discount. See you in Chicago!

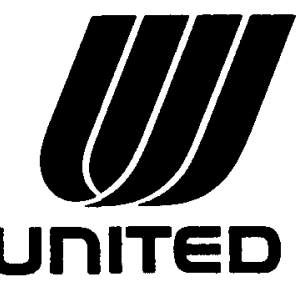

